\title{
CERÂMICA COM LODO DE ETA: EDUCAÇÃO AMBIENTAL E ARTÍSTICA E CAPACITAÇÃO COMO PONTES PARA A REALIZAÇÃO DE DIREITOS HUMANOS
}

\section{CERAMICS WITH WATER TREATMENT PLANT SLUDGE: ENVIRONMENTAL AND ARTISTIC EDUCATION AND TRAINING AS BRIDGES FOR THE REALIZATION OF HUMAN RIGHTS}

\author{
Vivian Ane Lopes Cabral ${ }^{(1)}$ \\ Engenheira Ambiental, mestre e doutora em Engenharia Civil, área de concentração Sanitária e Ambiental, Universidade \\ Federal de Viçosa. \\ Rafael Kopschitz Xavier Bastos \\ Engenheiro civil, Universidade Federal de Juiz de Fora; especialização em Engenharia de Saúde Pública, ENSP/Fiocruz, \\ e doutorado em Engenharia de Saúde Pública, University of Leeds/UK; Professor Titular Departamento de Engenharia \\ Civil, Universidade Federal de Viçosa.
}

E-mail(1): ane.cabral@yahoo.com.br

\begin{abstract}
RESUMO
Apresenta-se neste trabalho a experiência de um projeto de extensão, em que resultados de pesquisas de aproveitamento do lodo da ETA na produção de cerâmica artística são aplicados em atividades de educação ambiental e artística e capacitação com jovens e mulheres de extratos sociais de baixa renda. Trata-se de uma opção para o manejo do lodo de ETA que se apresenta a uma só vez como oportunidade de resolução de passivo ambiental, de trabalho e renda, de elevação de consciência ambiental e de promoção de direitos humanos.
\end{abstract}

\begin{abstract}
This work presents the experience of an extension project, in which research results on the use of water treatment plant (WTP) sludge in the production of artistic ceramics are applied in environmental and artistic education activities and training with young people and women from low-income communities. It is an option for the management of WTP sludge that is presented at once as an opportunity for solving environmental liabilities, of work and income, for raising environmental awareness and promoting human rights.
\end{abstract}

Palavras-chave: Aproveitamento de resíduos. Direitos Humanos. Lodo de ETA.

Key words: Human rights. Waste recycling. Water treatment plant sludge.

\section{INTRODUÇÃO}

No Brasil, ao longo dos anos, o destino dos resíduos (lodo) do tratamento de água para consumo humano tem sido o corpo d'água mais próximo à estação de tratamento de água (ETA), o que provoca impactos negativos consideráveis e constitui importante passivo ambiental. A Política Nacional de Resíduos Sólidos (BRASIL, 2010) preconiza a seguinte hierarquia para a gestão desses resíduos (categoria na qual se enquadra o lodo de ETA): (i) prevenção ou redução da geração; (ii) reutilização, reciclagem ou valorização; e (iii) disposição ambientalmente adequada. Como vantagens da reutilização e reciclagem se encontram a redução de impactos ambientais, da demanda de área para aterro de resíduos e dos custos de disposição final dos resíduos, além de agregação de valor econômico ao que antes era visto apenas como um resíduo a ser descartado. Nesse sentido, muito se tem estudado sobre a incorporação de lodo de ETA em material cerâmico, principalmente cerâmica vermelha para construção civil (tijolos e telhas) (TARTARI, 2008; TEIXEIRA et al., 2011; SILVA et al., 2015). Entretanto, pouca atenção tem sido dada à cerâmica artística, ornamental ou utilitária, apesar de, em tese, existir aí um grande potencial a ser explorado, devido ao maior valor agregado ao 
lodo neste uso e menor exigência de resistência do produto, o que pode ser traduzido em maior quantidade de resíduo incorporado.

O presente artigo resulta do trabalho de um grupo de pesquisa e extensão em "aproveitamento de resíduos do saneamento", que desde 2010 se dedica ao tema lodo de ETA / cerâmica artística. Os resultados da pesquisa (avaliação técnica das possibilidades de lodo de ETA UFV na produção de cerâmica artística) vêm sendo aplicados em projetos de extensão em parceria com uma entidade filantrópica que promove ações socioeducativas, complementares à escola pública, visando o desenvolvimento integral de pré-adolescentes e adolescentes (12 a 17 anos), e programas voltados para mulheres em situação de vulnerabilidade, "inseridas em um sistema social opressor, que vivem em situação de exclusão social e pobreza extrema". O projeto de extensão aqui abordado, intitulado Cerarte - Construindo arte em cerâmica de forma Sustentável e Criativa", foi inicialmente desenvolvido por três anos consecutivos -2014, 2015 e 2016, sendo retomado em 2018 e 2019.

Em 2010 as Nações Unidas reconheceram o acesso à água e ao esgotamento sanitário como um direito humano (DHAS), explicitando assim sua inserção no enquadramento internacional dos direitos humanos do Pacto Internacional sobre Direitos Econômicos, Sociais e Culturais (PIDESC), que preveem o direito de todas as pessoas a um nível de vida adequado, incluindo o direito à saúde, alimentação, moradia digna e educação (ALBUQUERQUE, 2014). Na realidade, o DHAS é condição para a realização de outros direitos humanos, pois não se pode conceber, por exemplo, direito à saúde plena e à moradia digna sem a realização do direito ao saneamento. Em uma lógica similar, esta é abordagem deste trabalho: como, a partir do saneamento se pode promover a realização de outros direitos básicos, como os direitos ao trabalho e renda, e o direito à educação com vistas ao, como previsto no PIDESC, "pleno desenvolvimento da personalidade humana e do sentido da sua dignidade" (no caso, educação complementar).

\section{METODOLOGIA}

O projeto inclui um componente de educação sanitária e ambiental, onde é explorado todo o ciclo de produção de água para consumo humano, desde a conservação de recursos hídricos, o tratamento da água, a geração e as oportunidades de aproveitamento de resíduos, além de aspectos mais gerais sobre o saneamento e suas relações com o meio ambiente e a saúde. A opção de se trabalhar com cerâmica artística para aproveitamento de lodo de ETA incorpora a dimensão lúdica e o componente de educação artística.

Do ponto de vista pedagógico, o projeto tem inspiração nos ensinamentos de Paulo Freire em "Pedagogia da Esperança" (FREIRE, 1996), sobre a necessidade da esperança para a existência humana e a necessária luta para fazê-la melhor. No campo da educação artística, a abordagem é da arte-educação e da arteterapia. Cabe esclarecer o conceito de arteterapia, no contexto de atelier terapêutico e não no contexto psicoterápico. Conforme Saviani (1997) "o atelier terapêutico integra a linguagem, a história da arte, o material, a técnica, os instrumentos, o processo e o produto. O foco está no desenvolvimento criativo na arte fazendo ponte para o criativo na vida do indivíduo". De acordo com Chiesa (2014) a arte tem um forte papel social, mas também pode facilitar um despertar para as emoções; por meio da arteterapia, a pessoa "tem a oportunidade de se tornar mais consciente de seu processo no contato com suas sensações e seus sentimentos, trabalhando a sua presença e o estar no mundo como uma consciência criadora". Sobre arte-educação, cabe citar Rodrigues, Souza e Treviso (p.117):

"A arte-educação pretende utilizar a arte no processo de formação humana para dar sentido ao sentir e a percepção de mundo do ser, utilizando-se das emoções e referências simbólicas (cultura, memória, criatividade) do indivíduo. Com isto pretende educar respeitando a cultura herdada e acrescentando conhecimento a fim de dar instrumentos ao aluno para que ele venha desenvolver uma capacidade intelectual para saber ser crítico dentro desta mesma cultura" 


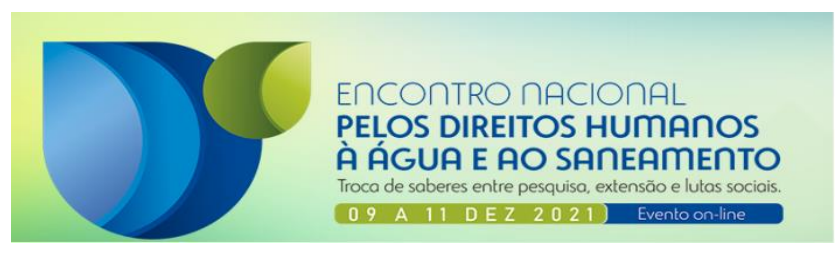

Do ponto de vista metodológico, o projeto tem sido realizado por meio de visitas guiadas a uma estação de tratamento de água e por oficinas de arteterapia (de curta duração) e de arte-educação (mais longas). As oficinas de arteterapia foram baseadas na abordagem denominada por Chiesa (2014), de "diálogo com o barro", que consiste de seis exercícios, simples, voltados para principiantes que pretendem adentrar o mundo da modelagem em cerâmica. Os exercícios começam com o reconhecimento do material, passando por várias etapas, até se chegar a uma construção mais elaborada. As oficinas de formação em cerâmica (arte-educação) seguiram um modelo convencional utilizado em cursos de cerâmica artística, sendo apresentadas técnicas reconhecidas de modelagem manual em cerâmica (FRIGOLA, 2006). Iniciou-se pela técnica da "bola" ou belisque, passando pelas técnicas do rolo ou acordeamento, finalizando com a técnica da placa. As peças produzidas nas oficinas foram queimadas e entregue aos(às) participantes.

\section{RESULTADOS ALCANÇADOS}

Ao longo de todo o projeto o projeto foi dirigido a pessoas (jovens e mulheres) atendidas pela entidade parceira. Os três primeiros anos foram dedicados a jovens de famílias de baixa renda. No primeiro ano foram desenvolvidas as oficinas de arteterapia de curta duração (para jovens de idades entre $12 \mathrm{e}$ 17 anos); no segundo, foram iniciadas as oficinas de longa duração, de caráter formativo, dirigidas à um público mais selecionado, e menor, de adolescentes. Ao longo desses três anos foram também realizadas oficinas de educação sanitária e ambiental, incluindo visitas à ETA. Naqueles anos enfrentava-se forte crise hídrica, aproveitando-se então a oportunidade para problematizar a situação e levantar questões como a necessidade de preservação de mananciais e uso racional da água. Ao todo, foram atendidos cerca de 150 jovens (Figura 1). Nesse período o projeto foi desenvolvido nas dependências da universidade.

Figura 1 - Visita guiada à ETA (esquerda) e oficinas de arteterapia - cerâmica com lodo de ETA (direita)
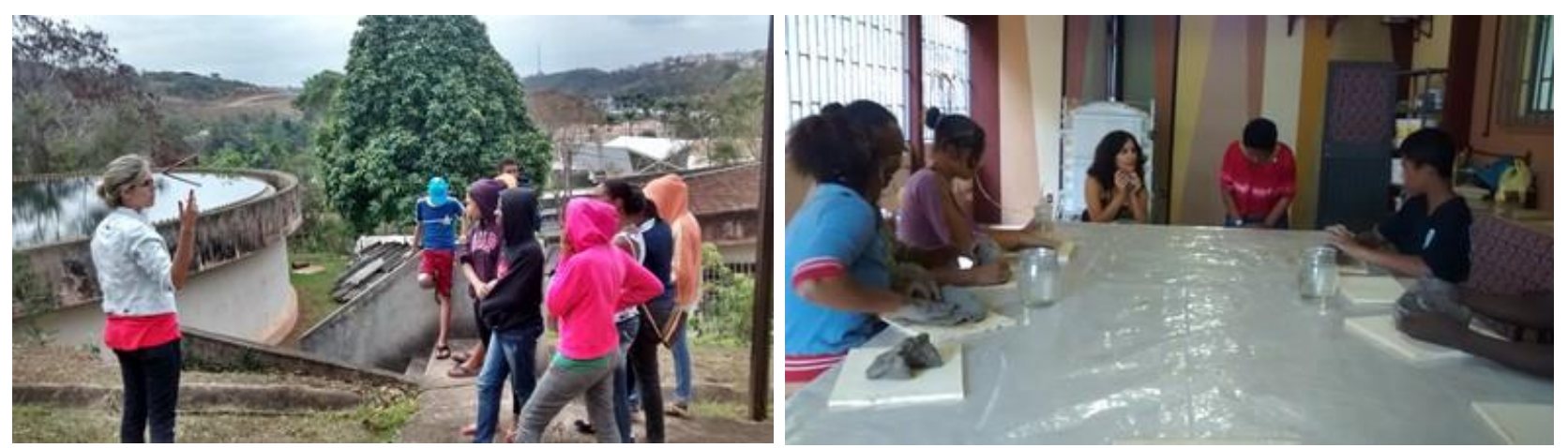

Fonte: acervo da autora.

No terceiro ano, o projeto atendeu um grupo dez mulheres em situação de vulnerabilidade social e nos dois anos seguintes ( 2018 - 2019) voltou ao atendimento de jovens (45 ao todo), nos dois casos em oficinas de capacitação em cerâmica (Figura 2). 

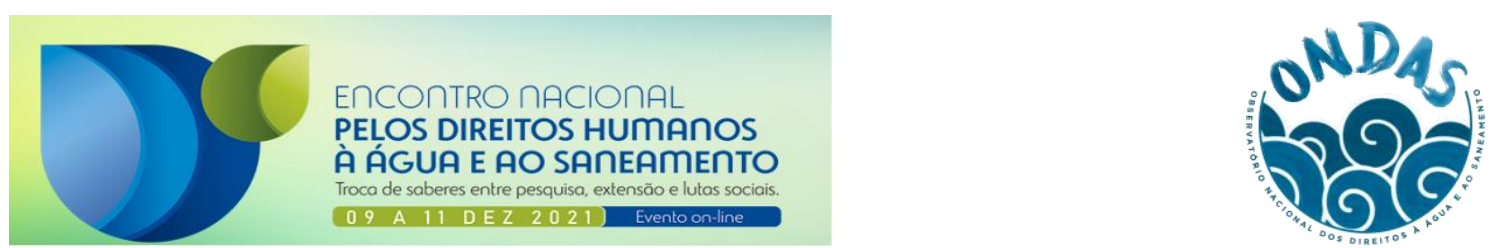

Figura 2 - Oficinas de capacitação com mulheres e (esquerda) jovens (direita) - cerâmica com lodo de ETA
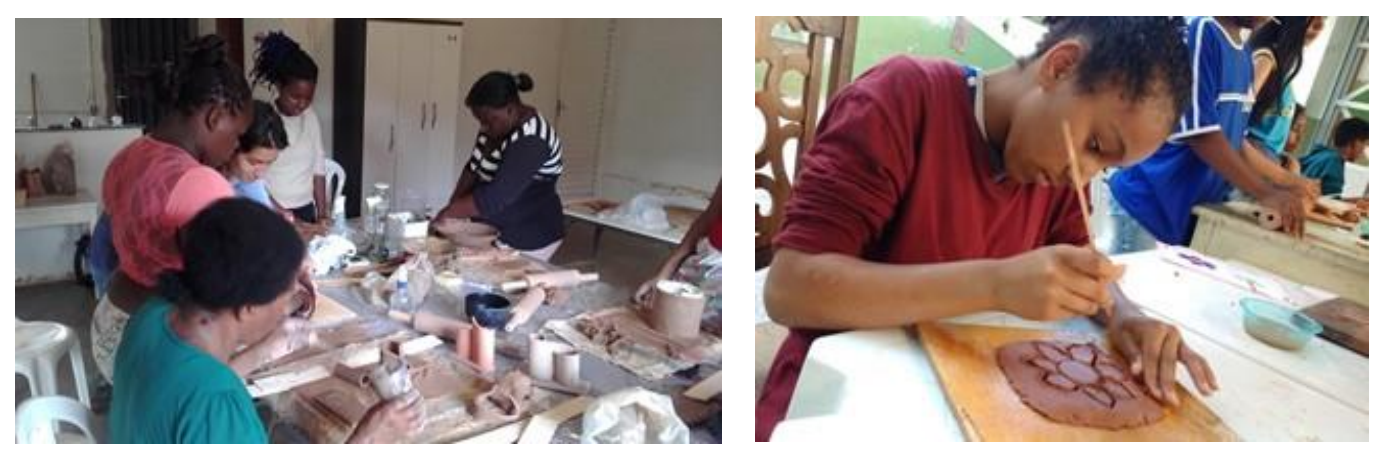

Fonte: acervo da autora.

Figura 3 - Cartilha utilizadas nas oficinas de educação sanitária e ambiental
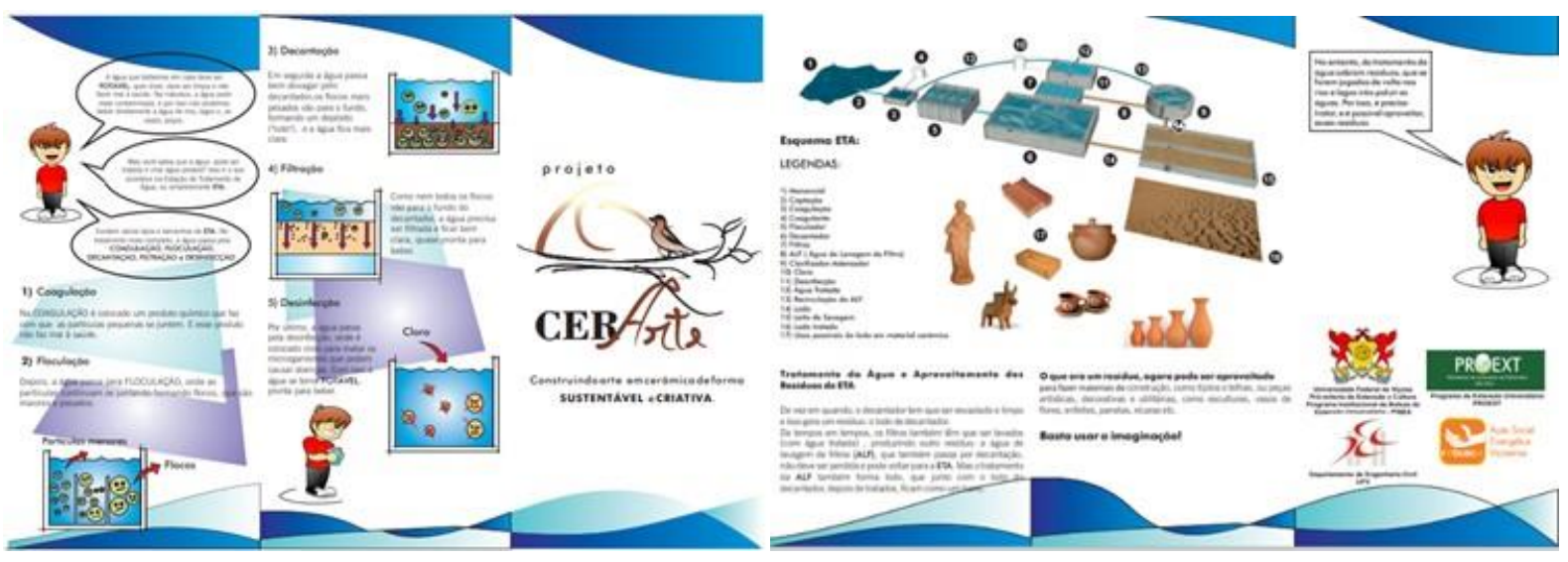

Fonte: acervo da autora.

Foi também confeccionada uma apostila para as oficinas de formação em cerâmica artística. O conteúdo versa sobre matérias-primas para cerâmica, argilas e técnicas de modelagem manual em cerâmica. O material foi preparado em linguagem apropriada, simples. As ilustrações foram pensadas para que houvesse identificação com o grupo (adolescentes, jovens e mulheres de extratos de baixa renda). 

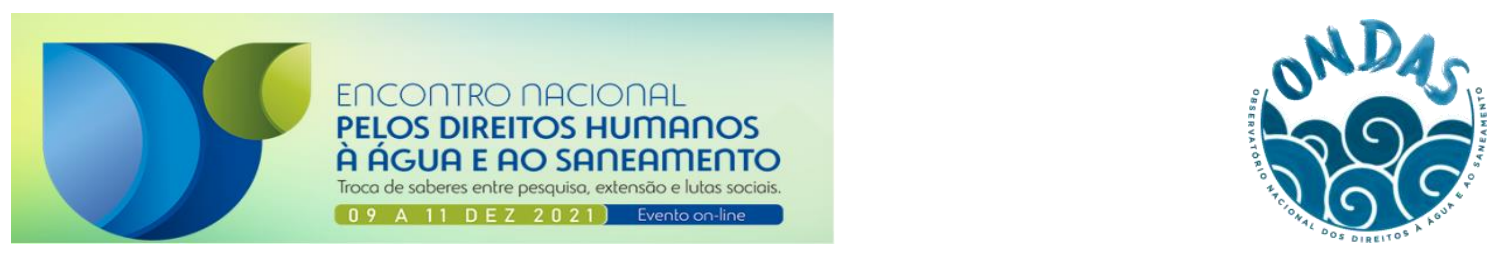

Figura 4 - Parte da apostila confeccionada para formação em cerâmica artística
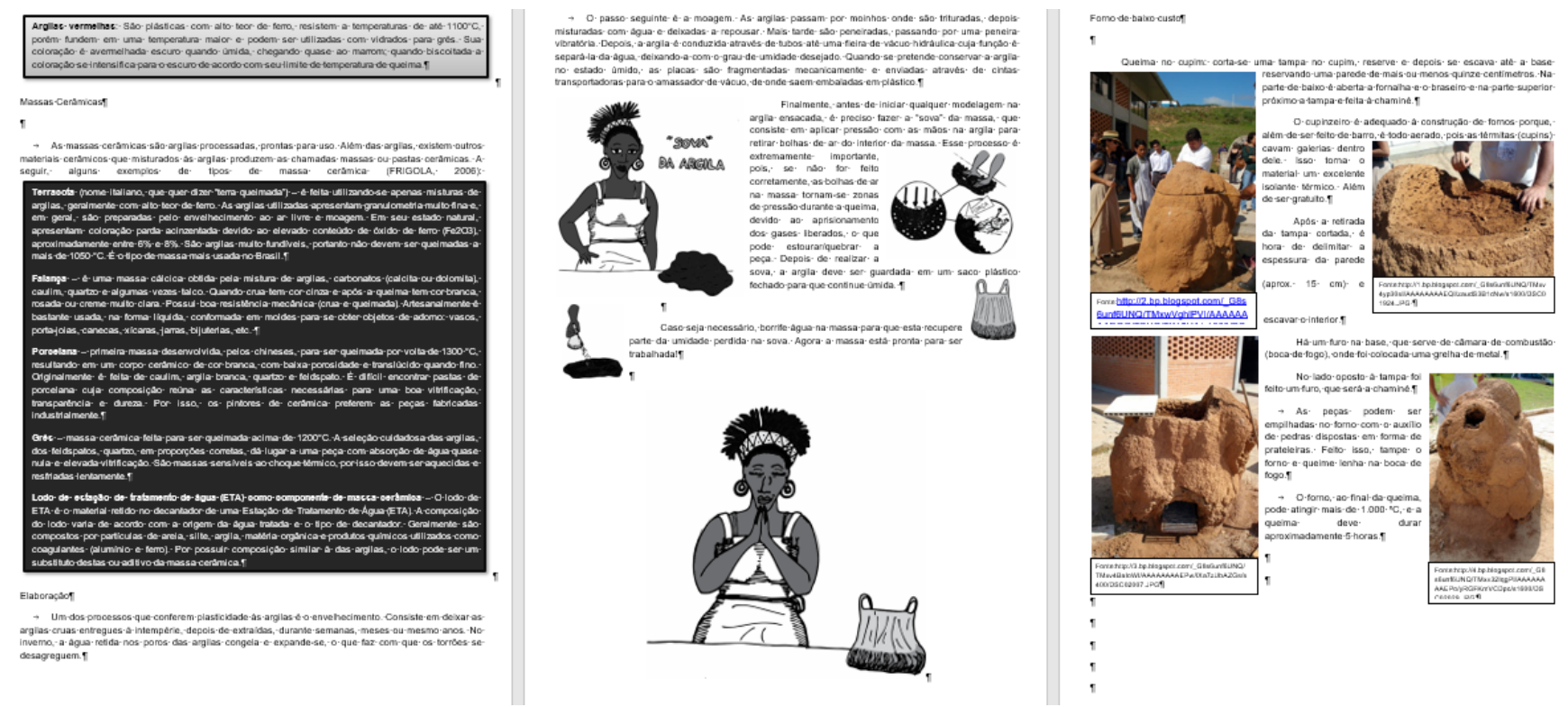

Fonte: acervo da autora.

Nas oficinas de cerâmica, era notória a limitação e inibição de algumas pessoas frente ao desafio de criar a partir de um maciço de argila. Entretanto, com o andar das oficinas , além de se sentirem mais familizariadas com o espaço e com o material, foram desenvolvendo suas habilidades manuais. Muitas pessoas relatavam relaxamento e calma após as atividades das oficinas. De maneira geral, ganhos de autoestima após execução de um trabalho (peça cerâmica) eram notórios. A Figura 5 apresenta os resultados das oficinas que aconteceram no primeiro semestre de 2015.

Figura 5 - Peças cerâmicas produzidas pelos jovens ao longo das oficinas de cerâmica realizadas no primeiro semestre de 2015

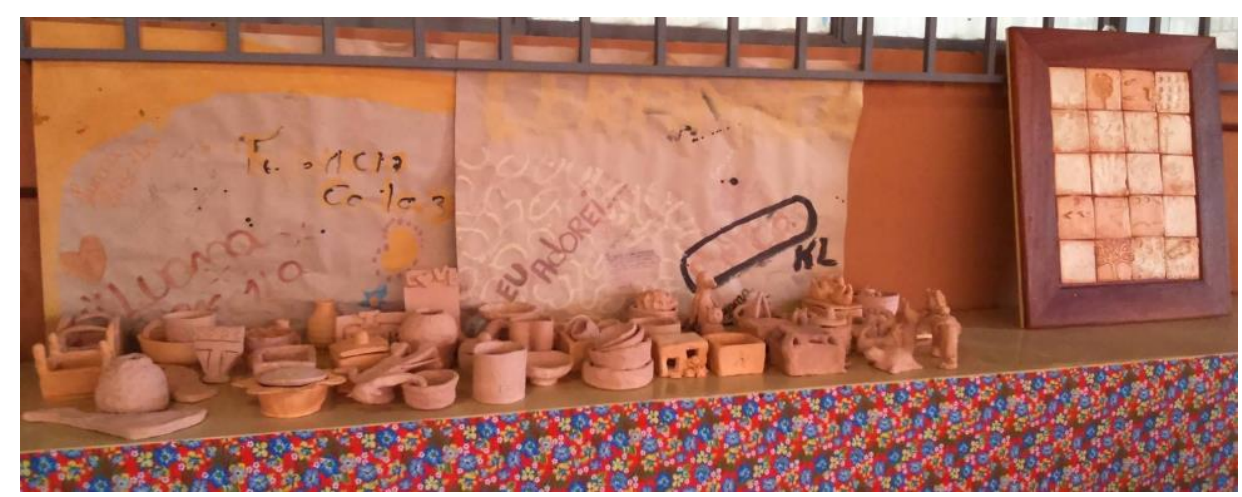

Fonte: acervo da autora.

\section{CONCLUSÕES}

Acredita-se que as atividades desenvolvidas contribuíram para processos de inclusão, autoestima, capacitação profissional e evolução artística e sociocultural de jovens e mulheres que vivem em situação de exclusão/vulnerabilidade social. Serviram também ao despertar de consciência crítica deste público sobre questões ambientais e de saneamento, em geral, e particularmente em relação à 
cidade em que vivem. Espera-se que tenham servido também para o despertar de interesse pelas artes à possibilidade de se encontrar na cerâmica uma fonte de trabalho e renda.

Por outro lado, o projeto oportunizou a estudantes de graduação vivência em atividades interdisciplinares e integradas de pesquisa e extensão, ou seja, a formação de recursos humanos com capacidade de reflexão crítica e transformadora.

Por fim, entende-se que este seja um exemplo de tecnologia social com grande poder de disseminação como experiência de economia solidária. A busca aqui é de uma nova opção para o manejo do lodo de ETAs de pequeno porte - a grandíssima maioria das ETAs em operação no Brasil -, constituindo ao mesmo tempo resolução de passivo ambiental e oportunidade de trabalho e renda para comunidades locais.

\section{REFERÊNCIAS}

ALBUQUERQUE, C. Manual prático para a realização dos direitos humanos à água e ao saneamento pela relatora especial da ONU, Catarina de Albuquerque. Cap. 1: Introdução. OHCHR, 2014

CHIESA, R. F. Diálogo com o barro: o encontro com o criativo. 3 ed. São Paulo: Casa do Psicólogo, 2014.

BRASIL, 2010. Lei $N^{\circ}$ 12.305, de 2 de agosto de 2010. Institui a Política Nacional de Resíduos Sólidos. Brasília, DF: Diário Oficial da União, 3.8.2010.

FREIRE, P. Pedagogia da Autonomia: saberes necessários à prática educativa. São Paulo: Paz e Terra, 1996.

FRIGOLA, M. D. R. i. Cerâmica Artística. Coleção artes e ofícios. 1 ed. Lisboa: Editorial Estampa, 2006.

RODRIGUES, R.N.L.; SOUZA, L. J.; TREVISO, V. C. Arte-educação: a relevância da arte no processo de ensino e aprendizagem. Cadernos de Educação: Ensino e Sociedade, v.4 , n.1, p.114126, 2017.

SILVA, E.M.; MORITA, D. M.; LIMA, A.C.M.; TEIXEIRA, L. G. Manufacturing ceramic bricks with polyaluminum chloride (PAC) sludge from a water treatment plant. Water Science and. Technology, v. 71, n. 11, p. 1638-1645, 2015.

TARTARI, R. Incorporação de lodo gerado na estação de tratamento de água Tamanduá, como aditivo em massas para cerâmica vermelha. Foz do Iguaçu, 2008. 124f. Dissertação (Mestrado em Engenharia Química) - Universidade Estadual do Oeste do Paraná, Foz do Iguaçu, 2008.

TEIXEIRA, S.R.; SANTOS, G.T.A.; SOUZA, A.E.; ALESSIO, P.; SOUZA, S.A.; SOUZA, N.R. The effect of incorporation of a Brazilian WTPs sludge on the properties of ceramic materials. Applied Clay Science, v. 53, p. 561-565, 2011. 